\title{
Wpływ technologii spawania rur ożebrowanych ze stali austenitycznej na strukturę połączenia rura - płaskownik
}

\author{
Impact of the technology of laser welding \\ of finned tubes made of austenitic steel on the structure \\ of the tube - flat bar joint
}

\section{Streszczenie}

W pracy przedstawiono wyniki prób technologicznych spawania laserowego rur ożebrowanych wykonanych ze stali austenitycznych w gatunku 304 (X5CrNi18-10) oraz 304H (X2CrNi19-10), ze szczególnym uwzględnieniem wpływu zmiennych parametrów spawania laserowego na strukturę połączenia rura - płaskownik. Stwierdzono, że technologia spawania laserowego rur ożebrowanych spełnia wymagania towarzystw kwalifikacyjnych, a struktura złączy zapewnia prawidłową wymianę ciepła w wymiennikach, przeznaczonych do pracy kotłów przy parametrach nadkrytycznych i ultranadkrytycznych.

Słowa kluczowe: stal austenityczna 304 i $304 \mathrm{H}$, spawanie laserowe, rury ożebrowane

\section{Abstract}

This article presents the results of technological tests of laser welding of finned tubes made of austenitic steels in the 304 (X5CrNi18-10) and 304H (X2CrNi19-10) grades, with particular attention given to the impact of the laser welding parameters on the geometry and structure of the tube - flat bar joint. It has been found that the laser welding technology applied in the finned tubes meets the requirements set by the licensing authorities, whereas the structure of the joint with a full penetration ensures a better durability of the joint and a correct heat exchange in heat exchangers intended for use in boilers with supercritical and ultra supercritical parameters.

Keywords: 304 and $304 \mathrm{H}$ austenitic steels, laser welding, finned tubes

\section{Wstęp}

Rozwój energetyki, głównego odbiorcy materiałów żarowytrzymałych, uzależniony jest w dużej mierze od materiałów i technologii spełniających coraz wyższe wymagania jakościowe. Dodatkowym bodźcem rozwoju tej gałęzi przemysłu są stale rosnące wymagania dotyczące ograniczenia emisji zanieczyszczeń, zwiększenie wydajności i niezawodności bloków energetycznych oraz obniżenia zużycia paliwa. Rozwój nowych materiałów i technologii energetycznych stał się podstawą badań prowadzonych na stalach austenitycznych stosowanych na rury ożebrowane w wymiennikach ciepła do pracy w warunkach nadkrytycznych i ultranadkrytycznych [1-3]. W zależności od parametrów termicznych, czynnika roboczego oraz spalin, konstrukcje te mogą być podgrzewaczami, ekonomizerami względnie przegrzewaczami. Zastosowanie spawanych rur ożebrowanych wyraźnie zwiększa sprawność termiczną kotłów, jest ona 2,5 razy większa w porównaniu ze sprawnością rur gładkich i 1,5 razy większa w stosunku do rur Faviera $[4,5]$. Właściwości które czynią stale austenityczne tak popularnymi to, wysoka odporność na korozję, dobra zdolność do odkształceń plastycznych, ciągliwość czy też - będąca tematem badań - spawalność.

\section{Materiał do badań}

Materiał do badań stanowiły rury ożebrowane spawane laserowo ( $\varphi$ 48,3 mm, grubość ścianki odpowiednio: stal $304-2,77 \mathrm{~mm}$, stal $304 \mathrm{H}-3,66 \mathrm{~mm}$, taśma $15 \times 1,0 \mathrm{~mm}$ ) wykonane ze stali austenitycznych w gatunkach 304 (X5CrNi18-10) oraz 304H (X2CrNi19-10), których skład chemiczny przedstawiono w tabeli I.

Próby technologiczne spawania laserowego przeprowadzono na automatycznej linii w Centrum Innowacyjnych Technologii Laserowych Energoinstal SA. Do spawania wykorzystano stanowisko z laserem dyskowym TruDisk 8002

Dr hab. inż. Janusz Adamiec, prof. PŚl; dr inż. Agnieszka Tomaszewska - Politechnika Śląska, Katowice 
Tablica I. Skład chemiczny badanych stali

Table I. Chemical composition of the steels

\begin{tabular}{|c|c|c|c|c|c|c|c|c|}
\hline \multirow{2}{*}{$\begin{array}{c}\text { Typ } \\
\text { stali }\end{array}$} & \multicolumn{7}{|c|}{ Skład chemiczny, \% wag. } \\
\cline { 2 - 9 } & $\mathrm{C}$ & $\mathrm{Cr}$ & $\mathrm{Ni}$ & $\mathrm{Mn}$ & $\mathrm{Si}$ & $\mathrm{N}$ & $\mathrm{P}$ & $\mathrm{S}$ \\
\hline 304 & $\max .0,08$ & $18-20$ & $8-10,5$ & $\max .2$ & $\max .0,75$ & $\max .0,10$ & max. 0,045 & max. 0,03 \\
\hline $304 \mathrm{H}$ & $0,04-0,1$ & $18-20$ & $8-10,5$ & $\max .2$ & $\max .0,75$ & - & max. 0,045 & max. 0,03 \\
\hline
\end{tabular}

Tablica II. Parametry spawania laserowego dla wybranych złączy Table II. Laser welding parameters for the selected joints

\begin{tabular}{|c|c|c|c|c|}
\hline Nr próbki & $\begin{array}{c}\text { Moc } \\
\text { wiązki } \\
\text { laserowej } \\
\text { kW }\end{array}$ & $\begin{array}{c}\text { Prędkość } \\
\text { spawania } \\
\mathrm{m} / \mathrm{min}\end{array}$ & Kąt 1 & Kąt 2 ${ }^{\circ}$ \\
\hline $304 \_1$ & 2,5 & 20 & 16 & 12 \\
\hline $304 \_2$ & 2,4 & 20 & 16 & 16 \\
\hline $304 \mathrm{H}_{1} 1$ & 2,3 & 20 & 16 & 12 \\
\hline $304 \mathrm{H}_{2} 2$ & 2,4 & 20 & 16 & 12 \\
\hline
\end{tabular}

firmy TRUMPF, wyposażone w światłowodowy system transmisji promieniowania laserowego rezonatora do głowicy roboczej oraz laserową głowicę spawalniczą z podwójną soczewką skupiającą o odległości ogniskowej f $=300 \mathrm{~mm}$ i kolimator $300 \mathrm{~mm}$. Parametrami regulowanymi podczas spawania była moc wiązki laserowej, która zmieniała się w zakresie od 2,0 do 2,6 kW, prędkość spawania, która wynosiła od 12 do $36 \mathrm{~m} / \mathrm{min}$ oraz kąt. Przetop złącza wykonany został w pozycji nabocznej PB. Szczegółowe parametry spawania przedstawiono w tabeli II.

Obserwacje struktury złączy przeprowadzono na zgładach metalograficznych trawionych elektrolitycznie w odczynniku Lucas Reagent $(50 \mathrm{ml}$ kwasu mlekowego $+150 \mathrm{ml}$ kwasu $\mathrm{HCl}$ + $3 \mathrm{~g}$ kwasu szczawiowego). Do tego celu użyto mikroskopu stereoskopowego firmy Nikon SMZ 745T oraz mikroskopu świetlnego Nikon Eclipse E200. W celu określenia rozkładu liniowego pierwiastków w spoinie i materiale rodzimym użyto elektronowego mikroskopu skaningowego Hitachi S-3400 wyposażonego w detektor EDS marki Thermo-Noran.

\section{Wyniki badań}

Badania wizualne wykonane zgodnie $z$ wymaganiami normy PN-EN ISO 13919-1:2002 oraz EN ISO 6520-1 wykazały, że tylko niektóre z parametrów spawania laserowego spełniają wymagane kryteria. Część złączy wykazuje bowiem powierzchniowe niezgodności spawalnicze, w postaci, np.: podtopień i przyklejeń (rys. 1a) oraz przyklejeń brzegowych i braku przetopu (wtopienia) (rys. 1b).

W dalszej części badań skupiono się na analizie złączy które pozytywnie przeszły etap badań wizualnych. Obserwacje mikrostruktury tych złączy nie wykazały żadnych mikropęknięć i potwierdziły prawidłową strukturę we wszystkich strefach połączeń dla obu badanych gatunków stali (rys. 2a i d). Spoiny charakteryzowały się budową dendrytyczną natomiast materiał rodzimy żebra i rury, miał strukturę austenityczną z widocznymi ziarnami bliźniaczymi. W obu przypadkach struktura żebra była bardziej drobnoziarnista w porównaniu do struktury rury. Oprócz tego w strukturze rury i taśmy ujawniono wydzielenia węglików, zarówno w środku ziaren (rys. 2f), jak i na granicach. W spoinie od linii wtopienia widoczne były kryształy kolumnowe, które wzrastały w kierunku odprowadzania ciepła (rys. 2b, $c$, e i f). Przeprowadzono również analizę składu chemicznego z wykorzystaniem systemu EDS, określając liniowy rozkład głównych pierwiastków stopowych na przekroju spoiny (rys. 3). Stwierdzono równomierny rozkład pierwiastków na przekroju poprzecznym złącza dla obu badanych stali. Porównując udziały masowe pierwiastków w poszczególnych spoinach, nie wykazano znaczących różnic pomiędzy stalą 304 i $304 \mathrm{H}$.
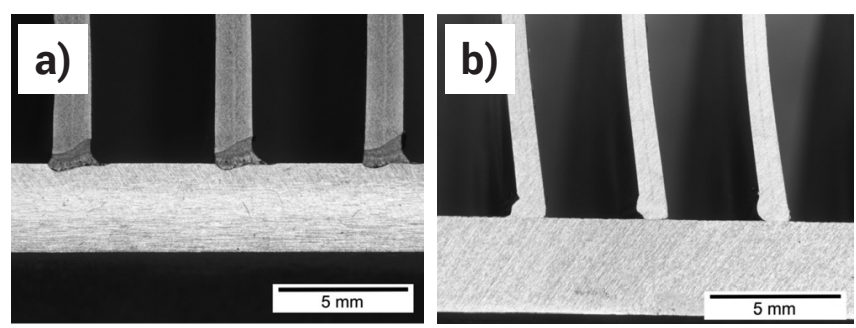

Rys. 1. Makrostruktura złączy, ocenione negatywnie, a) 304_2, b) $304 \mathrm{H} \_2$

Fig. 1. Macrostructure of joints, negatively evaluated, a) 304_2, b) $304 \mathrm{H} \_2$
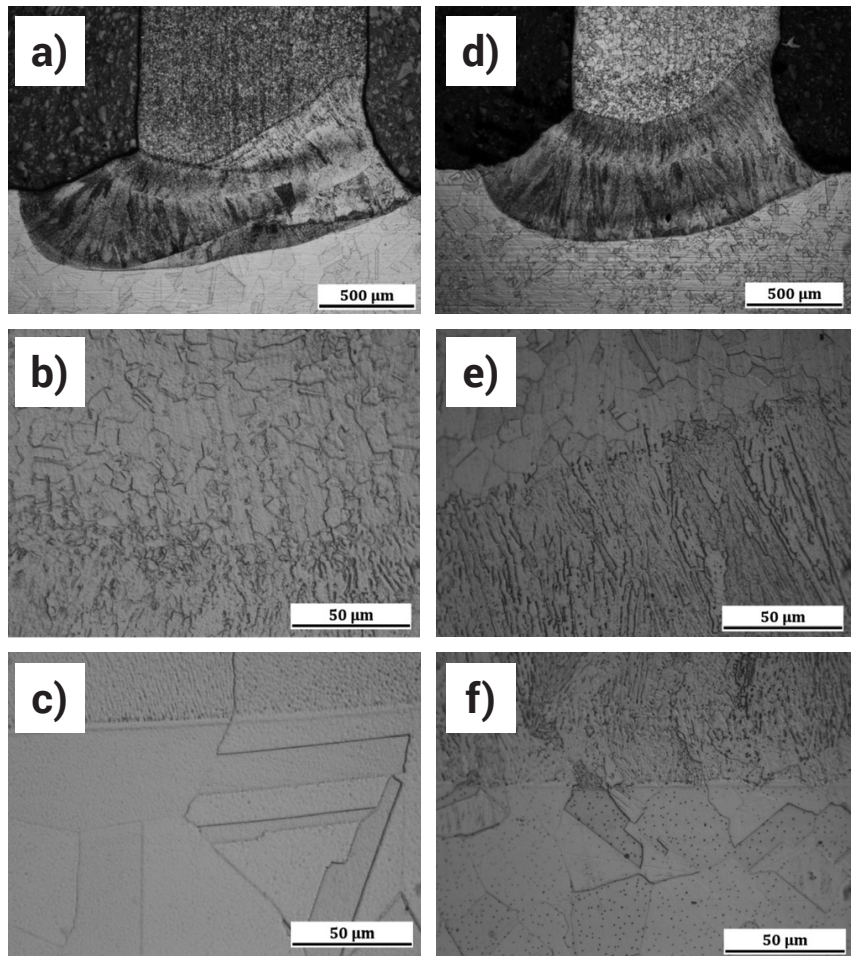

Rys. 2. Mikrostruktura złączy, ocenione pozytywnie, (a, b, c) 304_1; (d, e, f) - 304H_1

Fig. 2. Microstructure of joints, positively evaluated, (a, b, c) - 304_1; $(d, e, f)$ - 304H_1 
a)
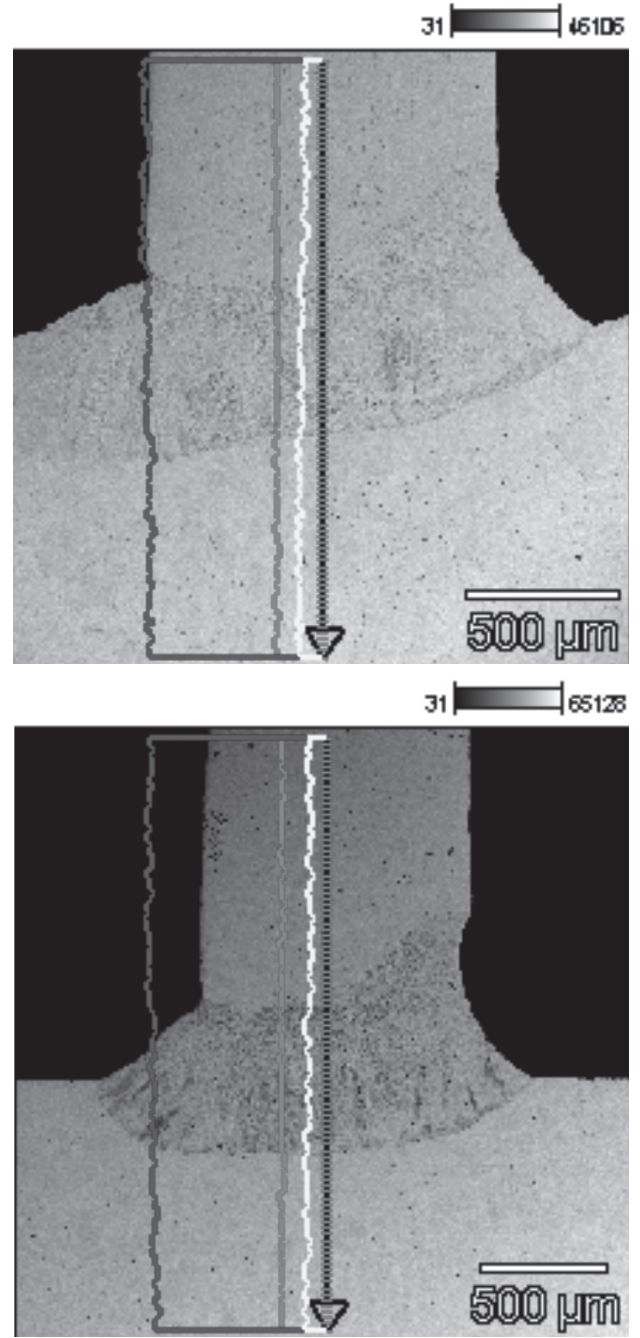
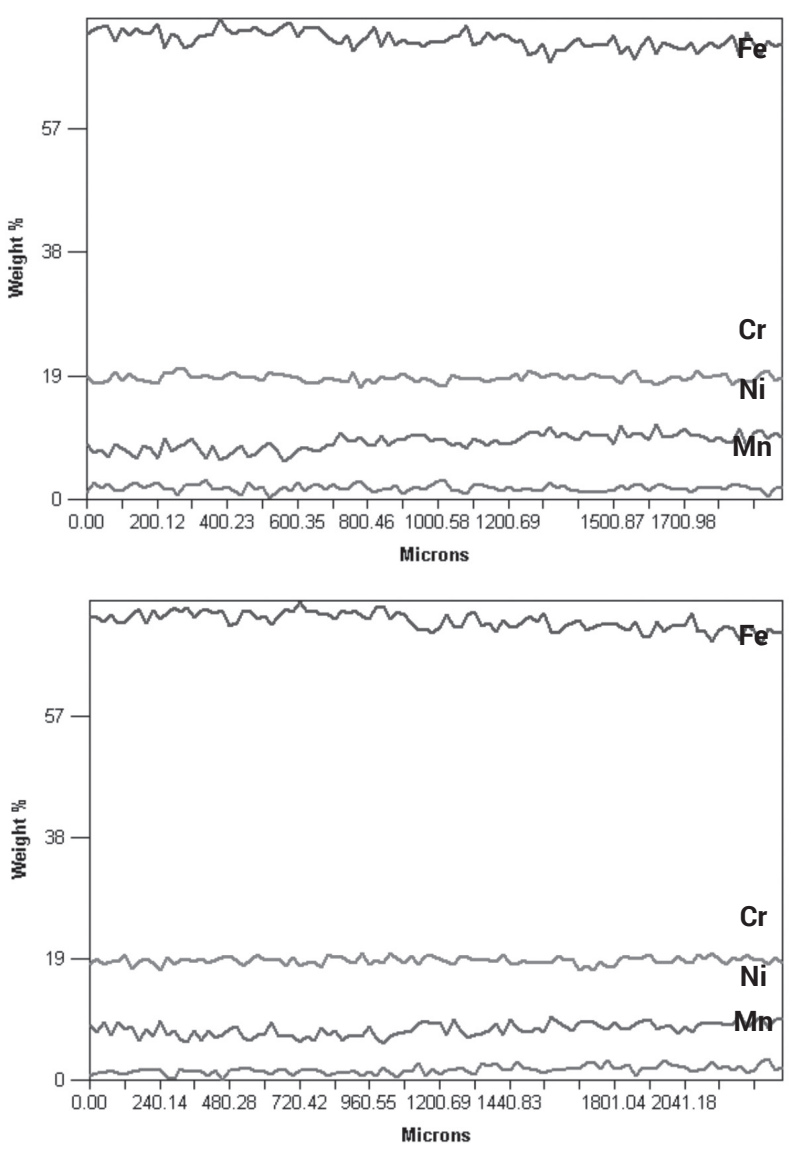

Rys. 3. Liniowy rozkład pierwiastków na przekroju spoiny, a) 304_1, b) $304 \mathrm{H}_{-} 1$

Fig. 3. Linear distribution of the elements in the cross section joints, a) 304_1, b) 304H_1

\section{Podsumowanie}

W artykule przedstawiono analizę wpływu zmiennych parametrów spawania laserowego na strukturę połączenia rura - płaskownik dla rur ożebrowanych wykonanych ze stali austenitycznych w gatunku 304 oraz 304H. Przeprowadzone na złączach badania wizualne wykonane zgodnie z wymaganiami norm (PN-EN ISO 13919-1 i EN ISO 6520-1) wykazały w części złączy powierzchniowe niezgodności spawalnicze. Określono optymalne parametry spawania, odpowiednio: dla stali $304-\left(\operatorname{moc} 2500 \mathrm{~W}\right.$, prędkość $20 \mathrm{~cm} / \mathrm{min}$, kąty $16^{\circ}$ i 12 $\left.{ }^{\circ}\right)$ natomiast, dla stali $304 \mathrm{H}-(\mathrm{moc} 2300 \mathrm{~W}$, prędkość $20 \mathrm{~cm} / \mathrm{min}$, kąty $16^{\circ} \mathrm{i} 16^{\circ}$ ), które pozwoliły uzyskać pełny przetop oraz łagodne przejście lica od żebra do rury. Badania mikrostruktury obu badanych stali potwierdziły strukturę austenityczną w materiale żebra i rury, natomiast spoiny charakteryzowały się budową dendrytyczną. Stwierdzono również równomierny rozkład głównych pierwiastków stopowych na przekroju poprzecznym spoiny dla obu badanych stali. Wykazano, że technologia spawania laserowego rur ożebrowanych spełnia wymagania towarzystw kwalifikacyjnych, a struktura złączy zapewnia prawidłową wymianę ciepła w wymiennikach, przeznaczonych do pracy kotłów przy parametrach nadkrytycznych i ultranadkrytycznych.

Praca sfinansowana $w$ ramach projektu PBS1/A5/13/2012, pt.: "Technologia spawania laserem rur ożebrowanych ze stali austenitycznych i stopów niklu przeznaczonych do pracy w kotłach o parametrach nadkrytycznych i ultranadkrytycznych" przez NCBiR.

\section{Literatura}

[1] A. Hernas, J. Pasternak, J. Brózda, G. Moskal, „Stale austenityczne i nadstopy niklu stosowane do budowy kotłów nadkrytycznych i ultranadkrytycznych", Wyd. SITPH, Katowice 2009, s.111-134.

[2] A. Hernas, „Żarowytrzymałość stali i stopów, cz.1”, Wyd. Pol. Śl., Gliwice 1999.

[3] J. Pasternak, S. Fudali, A. Hernas, M. Staszewski, „Stale austenityczne do zastosowań w kotłach o parametrach nadkrytycznych", Energetyka, Zeszyt tematyczny nr XVIII, 2008.
[4] J. Adamiec, M. Stopyra, M. Więcek, "Technologies of manufacturing finned tubes", Proceedings of 10th Liege Conference: Materials for Advanced Power Engineering, s.411-418, 2014.

[5] J. Adamiec, M. Więcek, G. Kokot, „Technologia spawania laserowego rur ożebrowanych" Przegląd Spawalnictwa, vol.86 (5), s.3-9, 2014 